\title{
Comparison of identification methods for oral asaccharolytic Eubacterium species
}

\author{
W. G. WADE, M. A. SLAYNE and M. J. ALDRED \\ Department of Oral Surgery, Medicine and Pathology, Dental School, University of Wales College of Medicine, \\ Heath Park, Cardiff CF4 4XY
}

Summary. Thirty one strains of oral, asaccharolytic Eubacterium spp. and the type strains of $E$. brachy, E. nodatum and $E$. timidum were subjected to three identification techniques-protein-profile analysis, determination of metabolic end-products, and the API ATB32A identification kit. Five clusters were obtained from numerical analysis of protein profiles and excellent correlations were seen with the other two methods. Protein profiles alone allowed unequivocal identification.

\section{Introduction}

Three oral, asaccharolytic Eubacterium species have been described-E. brachy, E. nodatum and $E$. timidum. ${ }^{1}$ They have been found to be virtually absent at healthy sites, present in gingivitis and common at sites with severe periodontal disease. ${ }^{2-5}$ However, they remain unfamiliar to many microbiologists because of their slow growth and fastidious nutritional requirements. Indeed, some workers, reporting comprehensive studies of the gingival and periodontal microflora, appear to have failed to isolate this group. ${ }^{6,7}$ Although originally described as periodontal species, they have been isolated from infections at other body sites. $E$. brachy has been isolated from pleural effusion ${ }^{8}$ and $E$. nodatum has been found in infections associated with intrauterine contraceptive devices. ${ }^{9}$

Members of this group have proved difficult to identify because they are generally unreactive in biochemical tests, although $E$. nodatum produces butyric acid, $E$. brachy iso-butyric, iso-valeric and iso-caproic acids ${ }^{1}$ and $E$. timidum produces phenylacetic acid, ${ }^{9}$ as major end products.

In this study, 31 strains of asaccharolytic Eubacterium spp., together with the type strains of $E$. brachy, $E$. nodatum and $E$, timidum, were subjected to three identification methods to assess the method most appropriate for rapid identification of clinical isolates.

Received 2 March 1990; accepted 2 May 1990.

\section{Materials and methods}

\section{Bacteria}

Thirty one isolates from chronic periodontitis (26) and acute pericoronitis (5) were taken from our departmental collection for this study. Isolates assigned to the group were slow-growing, anaerobic, asaccharolytic, grampositive bacilli. They had been stored at $-70^{\circ} \mathrm{C}$ in Brain Heart Infusion Broth (Lab M, Bury) with glycerol $20 \%$ and were revived and maintained on Fastidious Anaerobe Agar (FAA; Lab M). E. brachy ATCC 33089, E. nodatum ATCC 33099 and E. timidum ATCC 33093 were obtained from the American Type Culture Collection.

\section{Protein profiles}

Bacteria were grown on FAA for $72 \mathrm{~h}$, harvested and diluted 1 in $15(\mathrm{w} / \mathrm{v})$ with sample dissociating bufferdouble-distilled water $26 \mathrm{ml}$; glycerol $5 \mathrm{ml}$; sodium

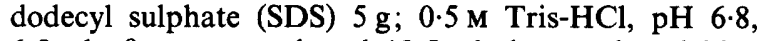
$6.5 \mathrm{ml} ; \beta$-mercaptoethanol $12.5 \mathrm{ml}$; bromophenol blue $0 \cdot 1 \%, 125 \mu 1 / \mathrm{ml}$. The organisms were disrupted by vigorous shaking for $5 \mathrm{~min}$ in a dental amalgam mixer (De Trey, Minerva Dental/Surgical Equipment and Supplies Ltd, Cardiff) with one-tenth volume $150-\mu \mathrm{m}$ diameter glass beads. Samples were boiled for $5 \mathrm{~min}$ and centrifuged at $14000 \mathrm{~g}$ for $4 \mathrm{~min}$. Protein profiles were produced by the PHAST system (Pharmacia, Milton Keynes) with 10-15\% gradient SDS-polyacrylamide gels. The system was programmed for an initial low output to draw samples slowly into the stacking gel $(100 \mathrm{~V}, 1.0 \mathrm{~mA}$, $1 \mathrm{~W}, 4 \mathrm{Vh}$ ), followed by an increased output step for separation $(250 \mathrm{~V}, 3.0 \mathrm{~mA}, 3 \mathrm{~W}, 66 \mathrm{Vh})$. Gels were stained with a modified Coomassie Blue stain (Phast Gel Blue R350 0.05\%; methanol 10\% v/v; acetic acid 9\% v/v; 


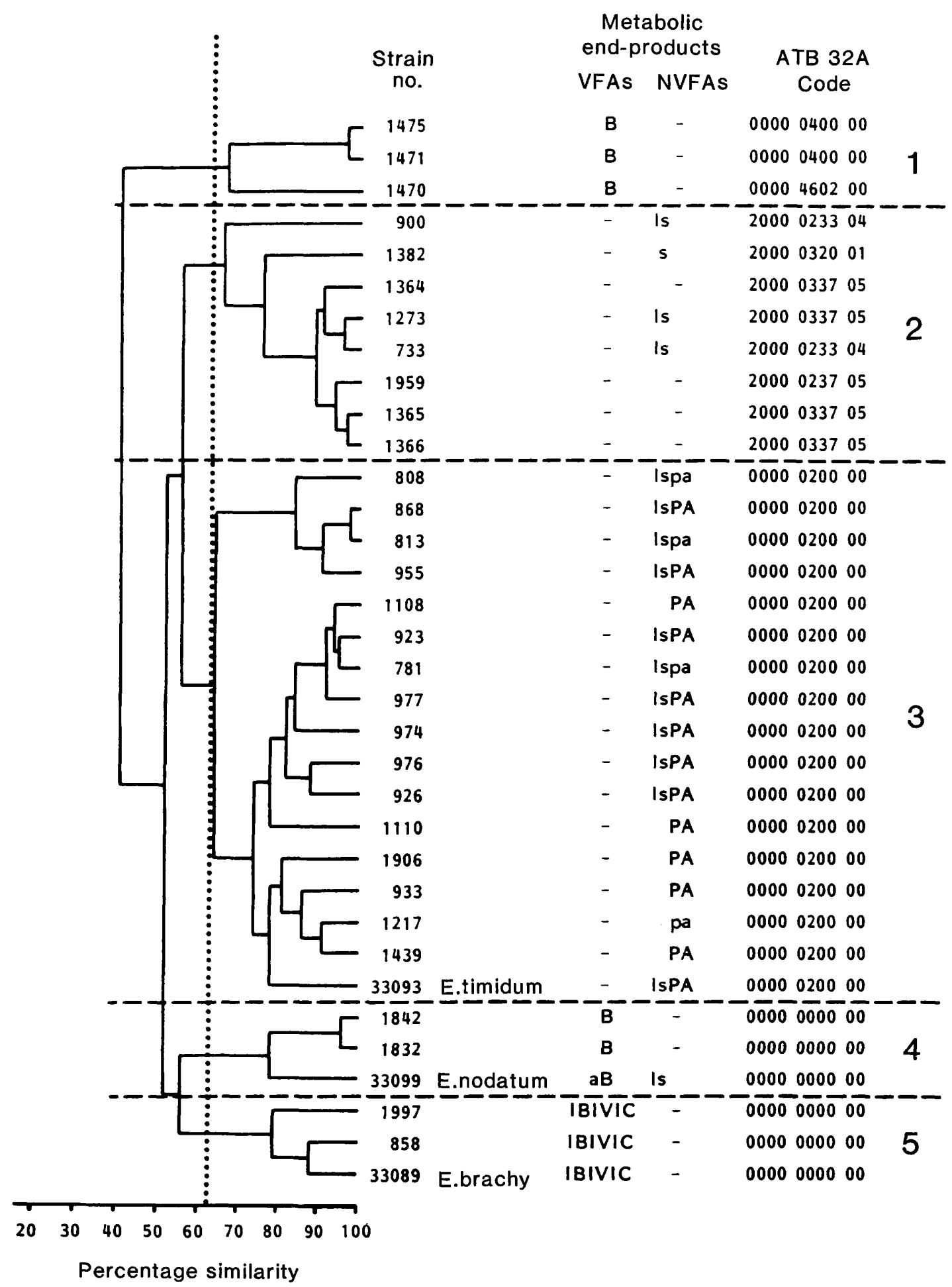

Figure. Cluster analysis, metabolic end-products and API ATB32A codes for asaccharolytic Eubacterium spp. Fatty acid metabolic end-products: a, acetic; ib, iso-butyric; b, butyric; iv, iso-valeric; ic, iso-caproic; 1 , lactic; s, succinic; pa, phenyl-acetic; lower case denotes minor peaks, upper case major peaks. 
ammonium sulphate $2 \% \mathrm{w} / \mathrm{v}$ in distilled water) and with acetic acid $10 \% \mathrm{v} / \mathrm{v}$ in distilled water for destaining. ${ }^{10}$ For densitometric analysis, each eight-track gel was regarded as two gels, each of four tracks. Molecular markers were run on each half of the gel to allow for gelto-gel correction of profiles. Gels were scanned with a Chromoscan 3 densitometer (Joyce-Loebl, Gateshead), and data were transferred directly to an Apricot XEN-i 386 microcomputer (Apricot Computers plc, Birmingham). All traces were normalised and correlation coefficients were determined. Cluster analysis was performed and a dendrogram was plotted to demonstrate similarities. The software used was developed from that described by Jackman. ${ }^{11}$

\section{Metabolic end-product analysis}

Metabolic end-product analysis was by gas chromatography with a Perkin Elmer 8410 chromatograph fitted with a flame ionisation detector (Perkin Elmer, Beaconsfield). A 1.8-m column packed with free fatty acid phase $10 \%$ was used and volatile and non-volatile fatty acids were extracted by standard methods. ${ }^{12}$

\section{API ATB32A}

The ATB32A kit (API-bioMerieux, Basingstoke) was used according to the manufacturers instructions. Bacteria were harvested from 72-h plates of Columbia Agar (Lab M) with sheep blood 5\% incubated anaerobically at $37^{\circ} \mathrm{C}$.

\section{Results}

The results are shown in the figure. Proteinprofile analysis resulted in five clusters at the $62 \%$ similarity level, three of which contained type strains. Metabolic end-products were consistent within clusters for the major acid products. Strains in clusters 1 and 4 produced butyric acid, whereas strains in cluster 3 produced a major phenyl-acetic peak. Strains in cluster 5 produced major isobutyric, iso-valeric and iso-caproic peaks and in cluster 2 , strains produced either no acids or small amounts of lactic and succinic acids.

The API ATB32A profiles were entirely consistent within clusters 3, 4 and 5. Proline arylamidase was the only positive test with strains in cluster 3 ; the strains in clusters 4 and 5 were unreactive in all tests. The two strains grouped most closely in

\section{REFERENCES}

1. Holdeman LV, Cato EP, Burmeister JA, Moore WEC. Descriptions of Eubacterium timidum sp. nov., Eubacterium brachy sp. nov., and Eubacterium nodatum sp. cluster 1 shared the same profile and a positive result in the leucyl glycine arylamidase test was unique to the strains in that cluster. Strains in cluster 2 exhibited the greatest heterogeneity of ATB32A profiles. Several positive test results were seen, particularly for aminopeptidases. Positive tests representative of this cluster were arginine dihydrolase and leucine arylamidase.

\section{Discussion}

The results of this study showed good correlation between the three methods. Used alone, metabolic end-product analysis would allow the identification of strains in clusters 2,3 and 5 but isolates in clusters 1 and 4 would not be distinguishable.

$E$. brachy, $E$. nodatum and $E$. timidum are not included in the API ATB32A database. The codes generated by the strains in this study were either not in the database or coded for a genus level or presumptive identification of Clostridium spp. The API kit could be used to identify strains in clusters 1,2 and 3 but those in clusters 4 and 5 could not be differentiated because they were unreactive in all tests. Therefore, protein profiles appear to be the most useful of the methods tested.

Although a number of un-named Eubacterium species isolated from periodontal disease have been described previously, ${ }^{2-5}$ their characteristics have not been reported. This makes it impossible to correlate those reports with the unnamed groups described in this study. Hill et al. ${ }^{9}$ have described the characteristics of a group designated D6, which produced butyric and phenyl-acetic acids, and thus did not correspond to any of the clusters in this study.

$E$. lentum phenotypically resembles all the strains described in this study but it has not been isolated from plaque samples in gingival health or disease $^{2-5}$ (and W. Wade, unpublished data), although it has been described frequently in other body sites. Growth of $E$. lentum is markedly stimulated by arginine, ${ }^{13}$ which is included in FAA, and allows easy differentiation of this species, should it be encountered, from the organisms described in the present study. Further taxonomic studies of the genus Eubacterium are clearly required.

nov. isolated from human periodontitis. Inst J Syst Bact $1980 ; 30$ : 163-169.

2. Moore WEC, Holdeman LV, Smibert RM et al. Bacteriology of experimental gingivitis in young adult humans. Infect Immun 1982; 38: 651-667. 
3. Moore WEC, Holdeman LV, Smibert RM, Hash DE, Burmeister JA, Ranney RR. Bacteriology of severe periodontitis in young adult humans. Infect Immun 1982; 38: 1137-1148.

4. Moore WEC, Holdeman LV, Cato EP, Smibert RM, Burmeister JA, Ranney RR. Bacteriology of moderate (chronic) periodontitis in mature adult humans. Infect Immun 1983; 42: 510-515.

5. Moore WEC, Holdeman LV, Cato EP et al. Comparative bacteriology of juvenile periodontitis. Infect Immun $1985 ; 48$ : 507-519.

6. Slots J. The predominant cultivable microflora of advanced periodontitis. Scand J Dent Res 1977; 85: 114-121.

7. Tanner ACR, Haffer C, Bratthall GT, Visconti RA, Socransky SS. A study of the bacteria associated with advancing periodontitis in man. $J$ Clin Periodontol $1979 ; 6: 278-307$.

8. Rochford JC. Pleuropulmonary infection associated with Eubacterium brachy, a new species of Eubacterium. $J$ Clin Microbiol 1980; 12: 722-723.
9. Hill GB, Ayers OM, Kohan AP. Characteristics and sites of infection of Eubacterium nodatum, Eubacterium timidum, Eubacterium brachy, and other asaccharolytic Eubacteria. J Clin Microbiol 1987; 25: 1540-1545.

10. Heukeshoven $J$, Dernick $R$. Increased sensitivity for Coomassie staining of sodium dodecyl sulfate-polyacrylamide gels using PhastSystem development Unit. Electrophoresis 1988; 9: 60-61.

11. Jackman PJH. Microbial systematics based on electrophoretic whole-cell protein patterns. In: Colwell $\mathbf{R}$, Grigorova R (eds) Current methods for the identification and classification of micro-organisms. Methods in microbiology vol 19. London, Academic Press. 1987: 209-225.

12. Willis AT, Phillips KD. Gas-liquid chromatography. In: Anaerobic infections, 2nd edn. London, Public Health Laboratory Service. 1983: 43-51.

13. Sperry JF, Wilkins TD. Arginine, a growth-limiting factor for Eubacterium lentum. J Bacteriol 1976; 127: 780-784. 